adding natriuretic peptides would improve clinical risk prediction for stroke or TIA in the STOP-HF population.

Methods The study included 1156 patients without known AF enrolled in the STOP HF follow-up study between 2006 and 2017. The end-point measured was Stroke/TIA. Baseline NTproBNP levels(NP), CHA2DS2-VASc, HAVOC and HATCH scores were recorded for all patients. Logistical regression analysis and receiver operating characteristic curve were used to estimate odds ratio and the diagnostic accuracy of the NP and clinical prediction scores for Stroke/TIA, respectively.

Results The mean age (SD) was 65.8 (10.1) years, 579 $(50.5 \%)$ were female, prominent co-morbidities were hypertension and diabetes (table 1). The median NTproBNP was 93 $\mathrm{pg} / \mathrm{ml}$ (IQR:53- 189). The endpoint of stroke/TIA occurred in $44(3.8 \%)$ of the population. Patients experiencing stroke/TIA over follow up were older, more likely to have baseline vascular and thromboembolic disease and higher baseline NTproBNP levels than those who did not experience stroke/ TIA during follow up. The median scores for the CHA2DS2VASc, HAVOC, HATCH were also higher at baseline higher in the new onset TIA/Stroke group.

All the clinical prediction scores as well as NTproBNP predicted Stroke/TIA (table 2). All clinical prediction scores

Abstract 5 Table 1 Population characteristics by incident stroke/ TIA $(n=44)$ or not $(n=1112)$ over follow-up

\begin{tabular}{|c|c|c|c|}
\hline & $\begin{array}{l}\text { Total population, } \\
\mathrm{n}=1156\end{array}$ & $\begin{array}{l}\text { New TIA/Stroke } \\
n=44\end{array}$ & $\begin{array}{l}\text { No new Stroke/TIA } \\
n=1112\end{array}$ \\
\hline Female, $\mathrm{n}(\%)$ & $579(50.5 \%)$ & $21(47.8)$ & $557(50.1)$ \\
\hline Age, mean (SD) & $65.8(10)$ & $70.9(9.5)^{\star}$ & $64.6(10)$ \\
\hline BMI (kg/m²), median (IQR) & $28(25-31)$ & $27(25.8-30.3)$ & $28(25-31.5)$ \\
\hline $\begin{array}{l}\text { SBP }(\mathrm{mm} / \mathrm{Hg}) \text {, median } \\
\text { (IQR) }\end{array}$ & 136(124-149) & $136(121-145.5)$ & $136(124-149)$ \\
\hline $\begin{array}{l}\text { DBP }(\mathrm{mm} / \mathrm{Hg}) \text {, median } \\
\text { (IQR) }\end{array}$ & $81(74-89)$ & $78(72-86.25)$ & $81.5(74-89)$ \\
\hline Heart rate, median (IQR) & $70(62-78)$ & $65(56-72.5)$ & $70(62-78)$ \\
\hline $\begin{array}{l}\text { Follow up time, mean } \\
\text { (SD) }\end{array}$ & $4.59(1.83)$ & $5.75(2.1)$ & $4.6(1.8)$ \\
\hline Hypertension, n (\%) & $874(75.6)$ & $39(88.6)$ & $835(75.1)$ \\
\hline Diabetes, $\mathrm{n}(\%)$ & $441(38.1)$ & $14(31.8)^{*}$ & $427(38.4)$ \\
\hline Stroke/TIA, n (\%) & $62(5.4)$ & $10(22.7)^{*}$ & $52(14.7)$ \\
\hline $\begin{array}{l}\text { Myocardial infarction, } \mathrm{n} \\
(\%)\end{array}$ & $101(8.7)$ & $7(15.9)^{*}$ & $94(8.5)$ \\
\hline $\begin{array}{l}\text { Peripheral Vascular } \\
\text { disease, } \mathrm{n}(\%)\end{array}$ & $27(2.3)$ & $4(9)$ & $23(20.7)$ \\
\hline COPD, n (\%) & $24(2.1)$ & $2(4.5)$ & $22(2)$ \\
\hline $\begin{array}{l}\text { Thomboembolic disease, } \mathrm{n} \\
\text { (\%) }\end{array}$ & $49(4.3)$ & $6(13.6)^{*}$ & $42(3.8)$ \\
\hline NTproBNP, median (IQR) & $93.3(53.1-182)$ & $\begin{array}{l}174(96.8- \\
283.3)^{*}\end{array}$ & $90.8(52.3-177.2)$ \\
\hline $\begin{array}{l}\mathrm{CHA}_{2} \mathrm{DS}_{2} \text {-VASc, median } \\
\text { (IQR) }\end{array}$ & $3(1,3)$ & $3.5(2,5)$ & $2(2,3)$ \\
\hline HATCH, median (IQR) & $1(1,1)$ & $2(1,2)$ & $1(1,1)$ \\
\hline HAVOC, median (IQR) & $2(2,3)$ & $4(2.8,5)$ & $3(2,4)$ \\
\hline
\end{tabular}

* asterisk denotes statistical significance in comparison with No new Stroke/TIA group. Abbreviations: $\mathrm{SD}=$ standard deviation $; \mathrm{IQR}=$ interquartile range $; \mathrm{BMI}=$ Body mass index $; \mathrm{SBP}=$ systolic blood pressure $; \mathrm{DBP}=$ diastolic blood pressure $; \mathrm{COPD}=$ chronic obstructive pulmonary disease ; $\mathrm{CHA}_{2} \mathrm{DS}_{2}$-VASC = congestive heart failure/left ventricular ejection fraction $\leq 40 \%$, hypertension, age $\geq 75$, diabetes, stroke/TIA/thromboembolism, vascular disease, age 65-74: HATCH = hypertenstion, age $\geq 75$, TIA/Stroke, heart failure, chronic obstructive pulmonary disease ; $\mathrm{HAVOC}=$ hypertension, age $\geq 75$, valvular disease, obesity, heart failure, coronary heart disease, vascular disease.
Abstract 5 Table 2 Multivariable models for prediction of stroke/ TIA ( $n=44)$ over follow-up

\begin{tabular}{lllllll}
\hline $\begin{array}{l}\text { Independent } \\
\text { variable(s) }\end{array}$ & $\begin{array}{l}\text { Uni/ } \\
\text { bivariate } \\
\text { OR }\end{array}$ & $95 \% \mathrm{Cl}$ & P value & $\begin{array}{l}\text { Multivariate } \\
\text { OR }\end{array}$ & $95 \% \mathrm{Cl}$ & P value \\
\hline CHA2DS2VASC & $1.8^{\vee}$ & $1.5-2.2$ & $<0.001$ & $1.7^{\wedge}$ & $1.4-2.1$ & $<0.001$ \\
HATCH & $3.4^{\vee}$ & $2.4-4.8$ & $<0.001$ & $3.2^{\wedge}$ & $2.2-4.7$ & $<0.001$ \\
HAVOC & $1.4^{\vee}$ & $1.2-1.6$ & $<0.001$ & $1.3^{\wedge}$ & $1.1-1.5$ & $<0.01$ \\
NTproBNP & 4.1 & $2-8.2$ & $<0.001$ & $1.4^{*}$ & $0.6-3.3$ & NS \\
\hline
\end{tabular}

adjusted for LogNTproBNP and follow up time

adjusted for follow time

* adjusted for age, gender, follow up time and baseline TE/vascular disease

Abbreviations: $\mathrm{OR}=$ odd ratio; $\mathrm{Cl}=$ confidence intervals, $\mathrm{CHA}_{2} \mathrm{DS}_{2}-\mathrm{VASC}=$ congestive heart failure/left ventricular ejection fraction $\leq 40 \%$, hypertension, age $\geq 75$, diabetes, stroke TIA/thromboembolism, vascular disease, age 65-74: HATCH = hypertenstion, age $\geq 75$, TIA/Stroke, heart failure, chronic obstructive pulmonary disease ; HAVOC = hypertension, age $\geq 75$, valvular disease, obesity, heart failure, coronary heart disease, vascular disease; $\mathrm{TE}=$ thromboembolic.

remained significant predictors of Stroke/TIA after multivariate adjustment. NP prediction was no longer significant (table 2). The HATCH score significantly outperformed the other scores with a c statistic of 0.76 (95\% CI, 0.69 - 0.78) (figure $1 \&$ 2). The c-statistic for the CHA2DS2-VASc and HAVOC scores were 0.69 (95\% CI, 0.61- 0.77) and 0.66 (95\% CI, $0.57-$ 0.74), respectively. Addition of NP did not improve the discriminatory power of any of the scores.

Conclusion All the clinical scores predicted Stroke/TIA in patients without known AF. However, the HATCH score significantly outperformed the CHA2DS2-VASc and HAVOC scores. Baseline NP levels, neither predicted Stroke/TIA, nor enhanced the prediction power of the clinical scores. Further evaluation of the HA2TCH score will delineate its potential value in clinical practice.

\section{THE ROLE OF ABLATION INDEX ON REPEAT PULMONARY VEIN ISOLATION PROCEDURES IN PERSISTENT ATRIAL FIBRILLATION: A SHORT TERM OUTCOME}

SJ Lennon, J Mannion, G Szeplaki, J Keaney, E Keelan, J Galvin, U Boles. Heart and Vascular Centre, Cardiology Department, Mater Private Hospital Dublin, Ireland

\subsection{6/heartjnl-2020-ICS.6}

Introduction Ablation Index (AI) is a novel catheter-based parameter developed to improve and increase efficacy and safety of Pulmonary Vein Isolations (PVI) in the treatment of Atrial Fibrillation (AF). This method involves the incorporation of contact force, time and power in deliverance of ablation lines. The aim of this study is to evaluate the impact of $\mathrm{AI}$ on the AF free burden over one-year post redo ablation for persistent AF. The study evaluates a secondary endpoint in medical management escalations post procedure.

Methods A retrospective single centre study of 39 patients (Mater Private Hospital, Dublin) who had redo ablations for persistent AF between the period of Jan 2016 till December 2019. We evaluated and analysed the efficacy of AI on redo PVIs in comparison to conventional established ablation techniques. Both groups were matched for age, gender, and duration of PeAF. Group 1 (17 patients) was the AI group with ablation index intervention and group 2 was the contact force (CF) -guided group with 22 patients. Each cardiologist carried 
out a minimum of 100 ablations per year to confirm the uniformity of performance. Patient follow-up data was analysed at staged intervals for one-year post procedure.

Inclusion criteria are: Patients must have had one prior PVI procedure for PeAF, complete follow up data available and all procedures completed using the Carto 3D Mapping System.

Statistical analysis was carried out using SPSS (IBM SPSS Statistic Version 26). A Kaplan Meier graph was generated to evaluate the AF free interval. All continuous variables were

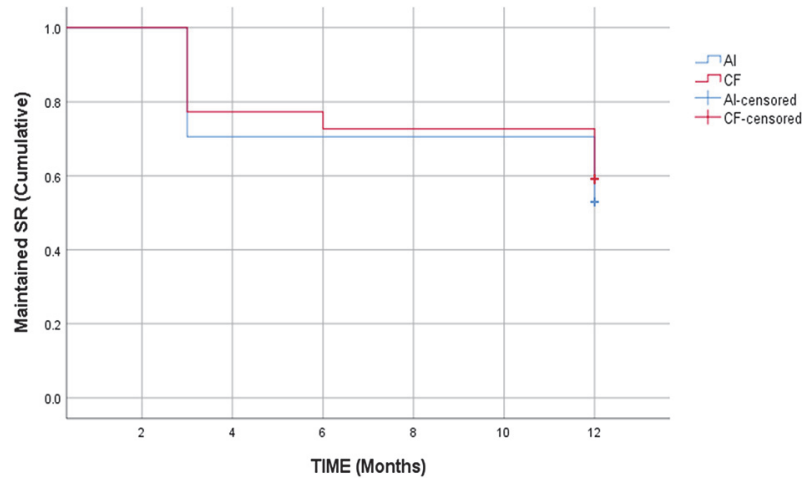

Abstract 6 Figure 1 Kaplien Meier Analysis of AF Free Burden Outcomes over 12 months

Abstract 6 Table 1 Depicts the demographic details, antiarrhythmic medications between $\mathrm{Al}$ group and standard $\mathrm{AF}$ ablation group

\begin{tabular}{|c|c|c|c|}
\hline & $\begin{array}{l}\text { Group } 1(\mathrm{Al}) \\
(\text { mean } \pm \mathrm{SD})\end{array}$ & $\begin{array}{l}\text { Group } 2(C F) \\
(\text { mean } \pm S D)\end{array}$ & $P$ Value \\
\hline $\mathrm{N}$ & 17 & 22 & 0.71 \\
\hline FEMALES (N, \%) & $18 \%$ & $26 \%$ & NS \\
\hline AGE (YEARS) & $62 \pm 10.5$ & $62 \pm 13$ & 0.38 \\
\hline WEIGHT (KG) & $95 \pm 16.8$ & $89.8 \pm 20.9$ & 0.32 \\
\hline Height (Metres) & $1.79 \pm 0.11$ & $1.8 \pm 0.9$ & 0.52 \\
\hline \multicolumn{4}{|l|}{ ATRIAL DATA } \\
\hline AVG DIAMETER (CM) & $3.09 \pm 0.39$ & $3.32 \pm 0.55$ & 0.12 \\
\hline AVG VOLUME (ML) & $4.6 \pm 0.94$ & $4.38 \pm 0.84$ & 0.66 \\
\hline AVG EF (\%) & $58 \pm 11$ & $61 \pm 11$ & 0.85 \\
\hline CHADVASC SCORE & 1.28 & 1.45 & 0.67 \\
\hline PV RECONNECTION & $17 / 17(100 \%)$ & 19/22 (86\%) & 0.1 \\
\hline \multicolumn{4}{|l|}{ ANTI-ARRHYTHMIC } \\
\hline BISOPROLOL & $6 / 17$ & $10 / 22$ & NS \\
\hline SOTOLOL & $7 / 17$ & $8 / 22$ & NS \\
\hline METOPROLOL & $1 / 17$ & $2 / 22$ & NS \\
\hline DRONDARONE & $1 / 17$ & - & NS \\
\hline FLECAINIDE & $3 / 17$ & 2/22 & NS \\
\hline AMIODARONE & $1 / 17$ & $3 / 22$ & NS- \\
\hline VERAPAMIL & $1 / 17$ & - & NS \\
\hline \multicolumn{4}{|c|}{ ANTI ARRHYTHMIC CHANGE } \\
\hline ESCALTION & $2 / 17$ & $7 / 22$ & 0.15 \\
\hline DESCALATION & $11 / 17$ & $6 / 22$ & $0.02^{*}$ \\
\hline NO CHANGE & $4 / 17$ & 9/22 & 0.27 \\
\hline
\end{tabular}

expressed as the mean \pm SD and Students $\mathrm{T}$ Test to was applied to give the significant differences for continuous variables.

Results Patient characteristics are demonstrated in Table 1. There were no significant differences in age, sex, weight, height, CHADVASC or anti-arrythmia agents, which indicated similar patient profile in each cohort. Pulmonary vein reconnections at redo PVI procedure were comparable at $100 \%$ in the AI group and $86 \%$ in the CF group $(\mathrm{p}=0.1)$. Freedom from $\mathrm{AF}$ burden was (mean $8.72 \pm 4.33$ months) in $\mathrm{CF}$ group Versus (mean $9.35 \pm 4.1$ months) in AI guided ablation $(p=0.71)$ (figure 1). The AI group demonstrated greater numbers of patients in whom antiarrhythmic therapy could be deescalated over one year (AI, $n=11 / 17,65 \%$ Vs. CF, $n=2$ / 22 , $9 \%$ with $\mathrm{p}=0.01$ ) while fewer patients underwent escalation of their antiarrhythmic therapy (AI $n=2 / 17,12 \%$ vs $\mathrm{CF}$ $\mathrm{n}=6 / 22,27 \% \mathrm{p}=0.03$ ) (table 1).

Conclusion This is the first study to analyse the outcomes of ablation index on repeat PVI procedures. Despite no significant difference in AF recurrence outcomes demonstrated in this study, there was a significant difference in the medical deescalation in favour of the use of the AI over the short term follow up period. This may reflect effective ablation lesions. A longer-term analysis would be recommended to determine the efficacy of AI use in PeAF redo procedures.

\section{THE CLINICAL UTILITY OF PET-CT IN THE MANGEMENT OF INFECTIVE ENDOCARDITIS}

D Hughes, C Gracias, Z Sharif, BF McAdam. Beaumont Hospital, Dublin, Ireland

\subsection{6/heartinl-2020-ICS.7}

Introduction The latest ESC guidelines on Infective Endocarditis (IE) included the use of PET-CT as an additional diagnostic criterion, particularly for prosthetic valve endocarditis, and several studies showed enhanced sensitivity for the modified Duke criteria. This audit was designed to assess if there was incremental clinical benefit of PET CT imaging in patients suspected of having IE.

Methods A two year retrospective audit was performed on consecutive patients diagnosed with IE, or had a PET-CT for investigation for IE in a large teaching hospital. The modified Duke criteria were used to establish a likelihood of IE and final diagnosis of IE was made based on all clinical information on discharge. The PET-CT scans were classified as having uptake at the site of interest, showed metastatic spread from endocarditis or were negative for either.

Results The audit identified 58 patients with a diagnosis IE or who had a PET-CT for investigation of IE. The mean patient age was 66 years and the in-hospital mortality was 14\%. In all of these cases apart from 1 the final diagnosis was infective endocarditis, either clinically or pathologically (after valve replacement). Of these 11 patients (19\%) had a PET-CT as part of their work up during their inpatient stay. Table 1 provides baseline demographics and clinical details of our cohort. For the patients that had a PET CT the mean age was younger at 55 years compared to 68 years ( $p$ value 0.003 ). As expected, the percentage of patients with prosthetic valves was also higher in the PET CT group at 55\% versus 13\% (P value 0.006). Otherwise there was no significant differences between the two groups. Table 2 outlines the results of the 11 patients who had a PET CT scan as part of their 